\title{
INFÂNCIAS PRESENTES EM ESCOLAS MULTISSERIADAS DA COMUNIDADE POMERANA NOS ANOS DE 1960
}

\author{
Juber Helena Baldotto Delboni ${ }^{1}$ \\ Gerda Margit Schütz Foerste ${ }^{2}$
}

\begin{abstract}
RESUMO: O artigo objetiva ampliar a compreensão acerca do acolhimento da criança pequena e da presença das infâncias nas classes multisseriadas. Tendo como recorte temporal os anos 1960 e geográfico, a comunidade tradicional pomerana de Caramuru, município de Santa Maria de Jetibá (ES), utiliza a análise de fotografia, tomada como fonte histórico-documental, obtida em acervo de moradores. Outras fontes de dados são a entrevista com a primeira professora da unidade escolar e a roda de conversa com moradores antigos, incluindo ex-alunos da escola. $O$ estudo se orienta pelo postulado de que as comunidades tradicionais são espaços de resistência e afirmação do território. A investigação dimensiona o papel da escola na comunidade pomerana, notadamente, no acolhimento à demanda por inclusão das infâncias, que se baseava nas necessidades e desafios próprios do contexto campesino, inclusive, escapando das normas oficiais.
\end{abstract}

Palavras-chave: Escola Multisseriada. Educação Infantil. Infâncias. Fotografia. Educação do Campo.

\section{CHILDHOODS PRESENT IN MULTI-GRADE SCHOOLS IN A POMERANIAN COMMUNITY IN THE 1960S}

\begin{abstract}
The article aims to broaden the understanding about the reception of small children and the presence of childhoods in multi-grade classes. As a time frame the 1960s and with geography the traditional Pomeranian community of Caramuru, municipality of Santa Maria de Jetibá (ES), uses photography analysis, taken as a historical-documentary source, obtained from a collection of residents. Other sources of data are the interview with the first teacher of the school unit and the conversation circle with former residents, including former students of the
\end{abstract}

\footnotetext{
${ }^{1}$ Doutoranda em Educação no Programa de Pós-graduação em Educação da Ufes. Pedagoga da Rede Municipal de Educação de Santa Maria de Jetibá (ES). E-mail: juberhelena@hotmail.com

${ }^{2}$ Licenciada em Educação Artística pela Federação dos Estabelecimentos de Ensino Superior em Novo Hamburgo (1986). Doutora em Educação. Docente do Departamento de Linguagens, Cultura e Educação e do Programa de Pós-Graduação em Educação da UFES. E-mail: gerda_foerste@yahoo.com.br
} 
school. The study is guided by the postulate that traditional communities are spaces of resistance and affirmation of the territory. The investigation measures the role of the school in the Pomeranian community, notably in welcoming the demand for inclusion of children, which was based on the needs and challenges of the rural context, even escaping from official norms.

Keywords: Multiseriada School. Child education. Childhoods. Photography. Rural Education.

\title{
INFANCIAS PRESENTES EN ESCUELAS MULTISERIALES EN UNA COMUNIDAD POMERANA EN LA DÉCADA DE 1960
}

\begin{abstract}
RESUMEN: El artículo tiene como objetivo ampliar la comprensión sobre la recepción de niños pequeños y la presencia de la infancia en clases de varios niveles. Con la década de 1960 como un marco de tiempo, y la geografía de la comunidad tradicional de Pomerania de Caramuru, municipio de Santa María de Jetibá (ES), utiliza el análisis de la fotografía, tomada como un fuente históricodocumental, obtenido de una colección de residentes. Otras fuentes de datos son la entrevista con el primer maestro de la unidad escolar y el círculo de conversación con antiguos residentes, incluidos los antiguos alumnos de la escuela. El estudio se guía por el postulado de que las comunidades tradicionales son espacios de resistencia y afirmación del territorio. La investigación mide el papel de la escuela en la comunidad de Pomerania, en particular al acoger la demanda de inclusión de niños, que se basó en las necesidades y desafíos del contexto rural, incluso escapando de las normas oficiales.
\end{abstract}

Palabras clave: Escuela Multiserial. Educación Infantil. Infancias. Fotografía. Educación rural.

\section{Introdução}

Lutas engendradas nos anos 1960, como a do Conselho Nacional dos Direitos da Mulher, encampada por profissionais da área da saúde, favoreceram a ação coletiva pela ampliação de espaços educativos voltados às crianças. O objetivo era atender às mães trabalhadoras urbanas. Mas foi somente mais tarde, com a Constituição de 1988, que a Educação Infantil passou a fazer parte da pauta da educação nacional e, mais 
recentemente, perspectivas se abriram para o atendimento a essa demanda no campo, ainda não plenamente contemplada.

O atendimento escolar às infâncias do campo é tema de intenso debate no cenário educacional e, cada vez mais, notamos denúncias relacionadas à ausência ou, ainda, à retirada de direitos fundamentais das crianças que vivem nas zonas rurais, em especial, o direito a frequentar escolas em suas próprias comunidades. Os gestores públicos vêm demostrando, assiduamente, o desrespeito ao art. 15 das Diretrizes Operacionais para a Educação Básica nas Escolas do Campo, que regula a oferta da Educação Básica aos povos campesinos (BRASIL, 2002).

Em 2009, menos de $30 \%$ das crianças do campo eram acolhidas pela Educação Infantil (IBGE, 2010). Como iniciativas para alavancar soluções que superassem esse deficit, foram criadas políticas públicas específicas para a Educação Básica do Campo (BRASIL, 2008); Diretrizes Curriculares Nacionais para Educação Infantil (BRASIL, 2009); Formação do grupo de trabalho para estruturação das Orientações Curriculares para Educação Infantil do Campo, além do Decreto 7.354/2010, que dispõe sobre a Política de Educação do Campo e o Programa Nacional de Reforma Agrária (BRASIL, 2010).

Como resultado dessas políticas, os dados do Censo Escolar 2018 (INEP, 2019) apontam para uma elevação, em nível nacional, de 11,1\% no atendimento à Educação Infantil no período 2014-2018. Contudo, o número de matrículas nessa modalidade não é nada animador para o meio campesino. Em 2018, conforme a mesma edição do Censo, apenas 224.221 crianças do campo estavam matriculadas em creches e 671.368, em pré-escolas. Logo, está longe de ser cumprida a universalização da Educação Infantil na Pré-Escola para as crianças de 4 e 5 anos, bem como a ampliação do atendimento em creches, de forma a atender, no mínimo, 50\% das crianças de até 3 anos, sendo ambas metas a serem alcançadas até o fim da vigência do atual Plano Nacional de Educação (BRASIL, 2014). 
Especificamente, este estudo busca aproximações com o contexto histórico vivido no início dos anos 1960, pela comunidade de Caramuru, Santa Maria de Jetibá (ES), para ampliar a compreensão acerca do acolhimento da criança pequena e da presença das infâncias nas classes multisseriadas. Nesse intuito, o olhar tem como referente temporal os anos 1960, estando focalizado em uma escola multisseriada, a Escola Singular Fazenda Borchardt, inaugurada em 1959.

Santa Maria de Jetibá é um município de colonização pomerana, cuja economia se baseia na agricultura familiar. Os pomeranos correspondem à maioria da população do município e mantêm tradições ancestrais. O bilinguismo é uma marca dessa comunidade, que é falante do pomerano, sua língua materna, e do português. Ali, a língua pomerana foi co-oficializada com a Lei 1.136/2009.

Antes disso, o Decreto 6.040/2007 (BRASIL,2007), que instituiu a Política Nacional de Desenvolvimento Sustentável dos Povos e Comunidades Tradicionais, reconheceu os pomeranos como povo tradicional, assim como fez com os povos indígenas e quilombolas. $\mathrm{O}$ art. 2 ㅇ desse dispositivo legal informa que o objetivo geral da política é o "[...] fortalecimento e garantia dos seus (dos povos tradicionais) direitos territoriais, sociais, ambientais, econômicos e culturais, com respeito e valorização a sua identidade, suas formas de organização e suas instituições" (BRASIL, 2007). A partir do Decreto $8.750 / 2016$, os pomeranos passaram a ter representação no Conselho Nacional dos Povos e Comunidades Tradicionais (BRASIL, 2016).

Brandão (2012) pontua que as comunidades tradicionais conseguem manter, no âmago, sua cultura, suas crenças, sua fé, suas maneiras de dançar e festejar e sua língua. Para o antropólogo, uma comunidade não é tradicional porque parou no tempo ou por não participar dos avanços tecnológicos contemporâneos; ela se caracteriza pela resistência ao projeto homogeneizador da cultura. Uma comunidade tradicional define um território, o qual, conforme Santos (1999, p. 08), “[...] é o fundamento do trabalho; lugar da residência, das trocas materiais e espirituais e do exercício da vida", 
fazendo, segundo seu argumento, oposição ao dinheiro e à exploração capitalista do trabalho. Nessa perspectiva, o território do povo tradicional pomerano é definido pelas tradições culturais repassadas pela oralidade, por artefatos, fotografias e pelas práticas cotidianas de cultivo da terra, culinária, educação, entre outras.

\section{Aproximações metodológicas acerca das imagens fotográficas como mediação}

A realidade dos fenômenos sociais não se revela de forma imediata, mas "fetichizada", pelo mundo das aparências. Sendo assim, a fotografia não se esgota na mensagem imediata, porque, silenciosamente, guarda um mundo que precisa ser revelado. Para Ciavatta (2008), a análise de fotografias como mediação implica incluir, como propriedade do objeto, as conexões temporais e espaciais que the são determinantes, pois "a mediação é o passo necessário para descrever a particularidade do objeto, a relação do aparente, singular ou contingente, com o processo mais amplo que o determina" (p. 48).

Posto isso, no acervo fotográfico de antigas professoras e moradores de Caramuru, buscamos as memórias da comunidade em relação às classes multisseriadas, para ampliar a compreensão acerca do acolhimento da criança pequena e da presença das infâncias nas classes multisseriadas. Neste estudo, destacamos para a análise uma dessas fotografias, que integra o acervo pessoal da primeira professora da Escola Singular Fazenda Borchardt.

Logo, a fotografia, neste estudo, foi tomada como fonte de pesquisa histórica (CIAVATTA, 2002; FOERSTE; SCHÜTZ-FOERSTE, 2012), constituindo-se como fonte documental e como monumento (LE GOFF, 1990), visto que materializa práticas históricas dos modos de produção de um dado lugar e tempo histórico. Portanto, a análise de uma fotografia pode "revelar" importantes indícios sobre a produção material e simbólica de uma comunidade. 
Adicionalmente, a análise e seus resultados são subsidiados por relatos obtidos a partir da entrevista com a primeira professora da Escola Singular Fazenda Borchardt e da realização de uma roda de conversa com moradores antigos da comunidade, a qual incluiu ex-alunos da unidade, inclusive os que ali estudaram quando ocorreu sua inauguração. A combinação dessas técnicas permite analisar, por exemplo, condições particulares de atendimento às infâncias em comunidade pomerana nos idos dos anos 1960, conforme mostramos a seguir.

\section{Infância, cultura e escola multisseriada em Santa Maria de Jetibá}

Os estudos acerca da cultura e, em especial, da educação de descendentes de imigrantes pomeranos são recentes (BAHIA, 2015; FOERSTE, 2016; FOERSTE; SCHÜTZFOERSTE, 2017). Especialmente nos últimos dez anos, foram desenvolvidas pesquisas sobre escolarização, preservação da cultura e práticas educativas que contemplem as demandas dessas comunidades (DETTMANN, 2014; HARTUWIG, 2011; KOELER, 2016; KÜSTER, 2015). Nelas, os pesquisadores já sinalizavam a importância da construção de propostas interculturais e bilíngues, no intuito de garantir o respeito aos direitos linguísticos e às diferenças culturais e étnicas dos alunos.

Nesse sentido, Hartuwig (2011) analisa o Programa de Educação Escolar Pomerana (Proepo), criado em 2005, com o objetivo principal de valorizar e fortalecer a cultura e a língua pomeranas, esta, nas formas oral e escrita. O programa foi implantado em Santa Maria de Jetibá e em outros quatro municípios do Espírito Santo (Domingos Martins, Vila Pavão, Pancas e Laranja de Terra), envolvendo ações, como aulas de língua pomerana nas escolas e formação continuada de professores que a falam. A autora atribui a criação do programa à capacidade do povo pomerano para articular parcerias interinstitucionais, fortalecidas em formas antigas de organização social, presentes nos primeiros tempos de colonização das terras que ocuparam em território capixaba. 
A partir da implantação do Proepo, Küster (2015) destaca que houve avanços nas escolas quanto ao uso da língua pomerana, observados nas opiniões de professores, pais e alunos. Ressalva, porém, que a língua materna desse povo é usada durante as aulas de pomerano e nos diálogos informais entre os alunos, de modo que os espaços que ela ocupa no ambiente escolar são restritos, havendo prevalência da língua portuguesa, do que emerge a necessidade de propostas interculturais e bilíngues.

Historicamente, os discursos em torno do bilinguismo das crianças pomeranas o sustentam como empecilho para sua alfabetização, sendo, portanto, responsáveis pelo seu insucesso na escola. Tais concepções tomam a língua hegemônica como a mais importante e se fundamentam no mito do monolinguismo, constituído desde as políticas de nacionalização do Estado Novo (1930-1937). Nessa direção, reforçam a ideia de assimilação cultural, tendo como fundamento a pedagogia autoritária, criticada por Freire (1970), porque é baseada na visão monocultural.

Em estudo sobre a escolarização do povo tradicional pomerano, Weber (1998) indica que quanto mais a prática educativa da escola estimula diálogos entre crianças e professores com base na cultura e nos saberes dos pomeranos, maior é a satisfação dos sujeitos, pois alcançam objetivos de leitura e produção textual propostos pelo currículo oficial e/ou prescrito. Por sua vez, Dettmann (2014) investigou como a prática de uma professora pomerana se ressignifica na interação com os saberes culturais, experienciais e coletivos produzidos na dinâmica escolar e comunitária. Conforme conclui seu estudo, essa prática possibilita o diálogo da cultura escolar com a cultura da escola, promovendo a vivência das experiências locais e o acesso ao saber universal. Investigações relativas às infâncias em comunidades tradicionais são particularmente recentes e se vinculam aos estudos sobre a sociologia das infâncias (SARMENTO, 2008). Siller e Araújo (2019) contextualizam o debate sobre as infâncias e sobre os direitos das crianças pomeranas, problematizando a educação monolíngue 
a que são submetidas quando chegam à escola. Observa a autora que, quando da chegada dos imigrantes em solo capixaba, em 29 de junho de 1859, os adultos vinham acompanhados de crianças de diversas idades. Ao longo do século XIX, a lista de imigrantes germânicos registrou mais de mil crianças, "entre meninos (522) e meninas (516), sendo 617 com idade até 6 anos e 421, na faixa de 7 a 12 anos, todos vindos da Pomerânia" (SILLER; ARAÚJO, 2019, p. 4).

Para o conjunto da população brasileira, o atendimento à Educação Infantil tem sido deficiente até hoje. Se na década de 1960 o debate sobre o assunto era incipiente e se restringia à reivindicação de creches para atendimento às mães trabalhadoras do meio urbano, estando o campo, lugar onde se encontram os pomeranos que vivem no Brasil, excluído dessa discussão, quando esse povo chegou ao País, a situação era ainda mais precária.

A produção das existências materiais e simbólicas e o atendimento às demandas escolares das crianças que acompanhavam os imigrantes adultos foram grandes desafios para o povo pomerano, pela ausência de políticas públicas educacionais de qualquer ordem. Particularmente, a falta de políticas para o atendimento às crianças pequenas do campo produziu práticas alternativas que, minimamente, resolvessem as necessidades da comunidade.

Em decorrência disso, nas igrejas luteranas, onde, ainda hoje, majoritariamente, esse grupo étnico professa sua fé, foram instaladas salas de aula em que se pudesse aprender a ler, escrever e contar. Além disso, muitas escolas comunitárias foram construídas em regime de mutirão. Em colaboração com lideranças, as crianças eram encaminhadas pelos pais à educação. Isso aconteceu até os anos 1930, quando o governo Vargas nacionalizou a educação (KÜSTER, 2015). Mulheres ou jovens da própria comunidade que tivessem mais tempo disponível e conhecimento eram convidadas para exercer a função de professora (FOERSTE; SCHÜTZ-FOERSTE; MERLER, 2014). 
Em geral, essas escolas possuíam uma única sala, configurando-se no que hoje denominamos escolas multisseriadas. Elas são caracterizadas pelo atendimento a alunos do 10 ao 5o ano e, ainda que possam ter mais de uma sala, em cada uma, concomitantemente, um único professor faz a mediação dos processos de produção do conhecimento para estudantes de diferentes idades e níveis de conhecimento.

As escolas multisseriadas têm presença marcante em Santa Maria de Jetibá, onde, em 2015, havia 29 delas em funcionamento, conforme dados fornecidos às pesquisadoras pela Secretaria de Educação de Santa Maria de Jetibá, inclusive a hoje denominada Escola Municipal Unidocente João Guilherme Germano Borchard, sobre a qual versa este estudo. Assim como investigações sobre a importância das escolas multisseriadas nas comunidades tradicionais campesinas (DELBONI, 2016; MORETO, 2015; MÜLLER, 2019), a análise de uma fotografia da inauguração da escola, destacada a seguir, permite-nos dimensionar sua atuação naqueles contextos para além de se aprender a ler, escrever e contar.

\section{A Escola Municipal Unidocente João Guilherme Germano Borchard}

A cena congelada na fotografia mostrada na Figura 1 é a cerimônia de inauguração da Escola Municipal Unidocente João Guilherme Germano Borchard, criada em 1959, em Caramuru, à época, denominada Escola Singular Fazenda Borchardt, construída pela comunidade no terreno doado pelo morador que lhe dá nome.

Conforme mostra a fotografia da figura 1, na inauguração da unidade, crianças, lideranças, pais e a comunidade em geral estavam presentes. Aproximando-nos da imagem, é possível observar alguns detalhes. Crianças estão, em pé, em uma sala, em meio a bancos, tábuas e caixotes de madeira. Os meninos vestem camisas brancas e bermudas até o joelho. Três meninas aparecem na fotografia, vestindo blusas brancas e saias franzidas. 


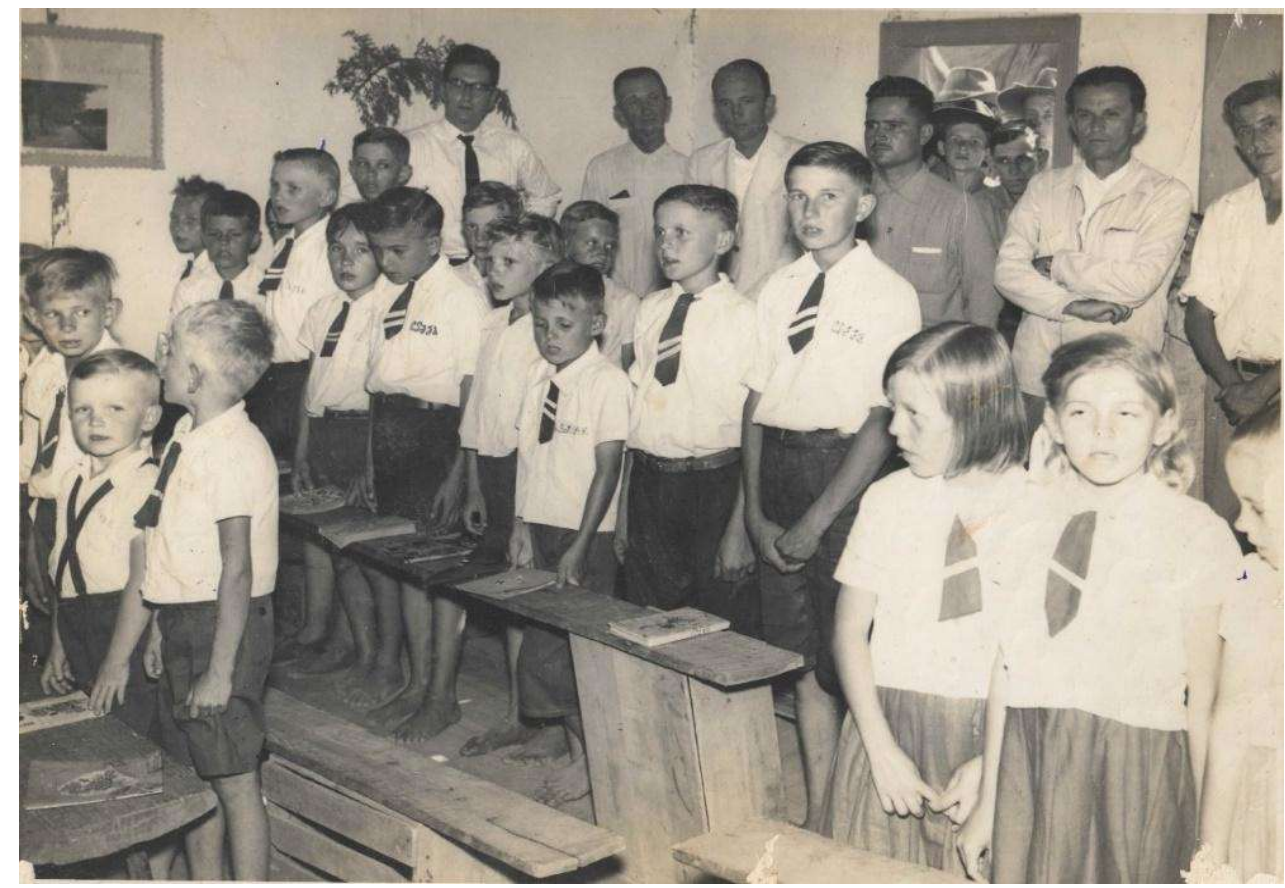

Figura 1 - Fotografia da Inauguração da Escola Singular Fazenda Borchardt ${ }^{3}$ Fonte: acervo pessoal de Dorothéa Göering Hartwig.

Observa-se ainda que a maioria usa uma gravatinha com uma ou duas listas, exceto um menino que está no banco da frente, com suspensório em " $x$ ", e outro, no banco de trás. Os meninos maiores usam cintos e todos aparecem descalços. Ao fundo, aparecem homens bem vestidos, sendo um deles com gravata. Na porta, vemos homens, a maioria de chapéu, ao que parece, querendo observar o que está acontecendo no interior da sala. Nas paredes brancas, um cartaz com uma gravura tem o seguinte título: "A primavera chegou".

Os alunos da fotografia se situam nas várias idades da infância; alguns são quase adolescentes, mas todos estavam no 10 e 20 anos, conforme as listas nas gravatas do uniforme, que serviam para indicar o ano cursado. Alguns já haviam cursado o primeiro ano em outra escola distante dali, mas a maioria nunca havia estudado. $\mathrm{O}$ anseio pela escola era grande, e ela demorou a chegar. Quando finalmente isso ocorreu, todos eles

\footnotetext{
${ }^{3}$ Fotografia $17 \mathrm{~cm} \times 23 \mathrm{~cm}$, em preto e branco, produzida pelo Serviço de Cinema, Rádio e Teatro da Secretaria da Educação e Cultura do Estado do Espírito Santo, em 13 de outubro de 1959.
} 
foram submetidos à alfabetização.

Com o fechamento das escolas paroquiais no período da nacionalização do ensino, a criação de escolas pelo governo não atendeu às comunidades de imediato. Por isso, a maioria da população do município ficou sem estudar. As poucas unidades ficavam distantes. No caso da comunidade de Jequitibá, hoje, Caramuru, apenas alguns alunos frequentavam a Escola de Rio das Pedras. Para isso, entretanto, precisavam percorrer, a pé, uma distância de mais de $6 \mathrm{~km}$. A filha do Sr. João Borchardt era uma dessas crianças, motivo pelo qual seu pai e outras famílias se empenharam para criar uma escola mais próxima de sua casa.

Iniciativas como a do Sr. João Borchardt, então líder da comunidade, eram comuns à época. Em reunião com os demais moradores, a construção foi aprovada e, então, a unidade começou a ser erguida por Emílio Holz, Augusto Treichel e Emílio Knaak. O início de suas atividades ocorreu em 29 de agosto de 1958, logo, mais de um ano antes da cerimônia retratada na fotografia. Havia 42 alunos matriculados, sendo 21 meninos e 21 meninas. Evidenciando os objetivos da criação da escola na comunidade, Dorothéa Göering Hartwig, primeira professora da unidade, narra, em entrevista para este estudo, que esta "nasceu do desejo do casal de agricultores pomeranos João Borchardt e sua esposa Laura Hartwig de ter uma escola de ensino público em língua portuguesa, diferindo-se do ensino em alemão, aplicado pelos pastores, antes da nacionalização.

A inauguração da Escola Singular Fazenda Borchardt foi um acontecimento histórico na comunidade, organizado e pretendido pela comitiva governamental, que, na ocasião, levou para ali o cinema, o que, conforme relato da professora Dorothéa, provocou grande admiração:

a caravana trouxe para a festa um filme, através do interventor, que admirou toda a comunidade presente, por nunca o terem apreciado. Isso só foi possivel porque, na propriedade do Sr. João, havia energia privativa, movida pela corrente de água que Deus forneceu e o homem soube utilizar. 
A criação da Escola Singular Fazenda Borchardt e de outras do período conformava um modelo de educação como integração do povo à nação, fortalecido com a proclamação da República. Era necessário produzir uma nova escola, organizada de acordo com os interesses do projeto educacional da nova ordem que então estava sendo implantada. Nesse período, foi atribuído à educação o papel de formação do cidadão republicano, consolidando o novo regime.

A fotografia deixa ver e, ao mesmo tempo, esconde o que não pode ser visto, em um jogo de claro e escuro, aparência e essência. Por isso, quando ela é alvo de análise, é preciso fazer a arqueologia do material e ir além do aparente (KOSIK, 1976). A fotografia da Figura 1 projeta o modelo de escola apregoada pelos republicanos, a criação da identidade nacional e a homogeneização cultural e linguística. A presença das autoridades reflete o domínio ideológico que se queria ter sobre as populações étnicas, tentativa de se implantar o nacionalismo e o desenvolvimento econômico.

A fotografia projeta o modelo da escola republicana também pelas crianças uniformizadas, pela separação de meninos e meninas em lados diferentes da sala, pelas crianças penteadas e em posição tida como de respeito para cantar o hino nacional. No entanto, não consegue esconder a origem humilde dos imigrantes pomeranos, com seus pés descalços, e o descaso com a escola rural, funcionando com caixotes com os quais se improvisavam as carteiras.

\section{A fotografia revelada: infâncias em classe multisseriada na comunidade tradicional pomerana de Santa Maria de Jetibá}

Tentamos descongelar a cena da Figura 1 e penetrar além da superfície do papel fotográfico, no intuito de nos aproximarmos dos sujeitos em seus contextos e territórios de vivência. Procedendo assim, nela, somos atraídos pelo olhar do menininho de suspensório (Figura 2). 


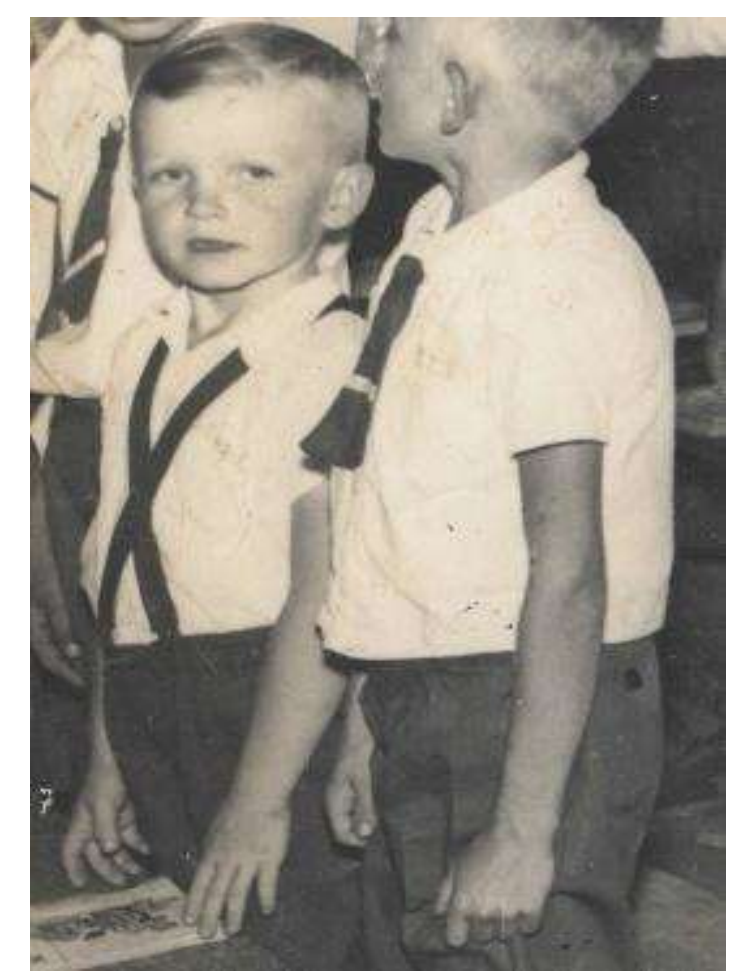

Figura 2: Detalhe da fotografia da inauguração da Escola Singular Fazenda Borchardt Fonte: recorte obtido a partir de fotografia do acervo pessoal de Dorothéa Göering Hartwig.

O olhar do menininho se destaca e alcança a objetiva da câmera fotográfica. Ele parece atento. A fotografia em análise nos remete a uma outra maneira de ver a infância, submetida a padrões rígidos de comportamento, como forma de a criança se assemelhar aos adultos. Percebemos que o enquadramento feito pelo fotógrafo destaca a figura dos adultos mais ao fundo da sala, não havendo preocupação em retratar todas as crianças - como dito, 42 no total. A fotografia, portanto, revela a invisibilidade das infâncias que frequentavam as escolas em meados do século passado.

Sarmento (2004) entende que essa concepção dominante da infância remete as crianças a um estatuto pré-social. Para esse autor, nela, as crianças são "invisíveis", porque não são consideradas como seres sociais de pleno direito. Tal condição se estende aos sujeitos do campo, de forma geral, quando não têm seus direitos básicos assegurados. Escolas são fechadas; faltam hospitais; a cultura, a arte e o conhecimento 
dessa população são sistematicamente desconsiderados. A imagem remonta a um tempo vivido, mas também permite avaliarmos nosso próprio tempo e as questões que se relacionam aos sujeitos campesinos.

$\mathrm{Na}$ roda de conversa realizada no âmbito deste estudo, percebemos que a infância permanece na memória dos ex-alunos da escola que ali estavam presentes. Projetada no quadro, a fotografia da inauguração provocou risos e burburinhos. Uma das participantes da roda de conversa, Dona Sabina Prochnow, que só fala pomerano, fez o seguinte relato, traduzido por Elenita, servente da escola. "No dia da prova, a professora trazia um potinho de tinta e cada criança ia lá e molhava a ponta da caneta. Era uma caneta diferente. Então, aquele dia era um dia especial, porque só naquele dia as crianças escreviam de caneta".

A criação da escola com classe multisseriada representou um marco na comunidade. Naquele espaço reuniam-se mulheres, lideranças, sendo, também, o lugar de encontros festivos. A tarefa educativa ali iniciada era ampliada na interlocução com a comunidade. Em roda de conversa, moradores antigos de Caramuru relataram que o menininho da Figura 2 não tinha a idade adequada para a matrícula, em razão do que não usava a gravatinha, embora frequentasse a escola. Conforme esses relatos, naquela época, era comum a frequência de crianças menores de cinco, seis anos à escola. Sendo ou não permitido, geralmente, elas acompanhavam os irmãos maiores até a escola cotidianamente. Assim, podiam se acostumar ao trajeto, ao ambiente escolar, além de aprender a falar a língua portuguesa, já que, na convivência familiar, utilizavam apenas o pomerano.

O encontro com crianças maiores e as trocas de conhecimentos favoreciam a socialização da criança pequena nas classes multisseriadas, o que colaborava, também, para o atendimento à demanda da mãe trabalhadora do campo. Como as comunidades tradicionais pomeranas são, majoritariamente, baseadas na agricultura familiar, em diversos momentos, além dos afazeres domésticos, a mulher realiza o trabalho agrícola 
e pecuário. O envio da criança pequena às classes multisseriadas, nesse caso, significava não apenas o atendimento às demandas imediatas, mas, também, uma estratégia de resistência. Com a socialização da criança pequena, mesmo sem as condições ideais, as famílias puderam perceber que aquele espaço lhes pertencia, sentimento que se mantém até hoje, conforme percebemos nos relatos durante a roda de conversa.

Esse pertencimento pode ser notado, também, pelo fato de que, ao concluir a então 4ạ série, algumas crianças repetiam o ano, uma vez que não havia como continuar os estudos da segunda etapa do Ensino Fundamental, na época, chamado ginásio. A expansão da permanência na escola era prática frequente e se dava pela intimidade com aquele espaço, pelo sentimento de dele fazer parte e pela acolhida ali recebida.

\section{Considerações finais}

A omissão do Estado brasileiro levou a comunidade pomerana de Santa Maria de Jetibá ao trabalho em mutirão, edificando escolas com classes multisseriadas e delas fazendo uso para atender as suas carências imediatas, entre elas, as relacionadas ao atendimento às crianças pequenas. No presente estudo, a partir da fotografia que, especificamente, retrata um momento da inauguração da Escola Singular Fazenda Borchardt, analisamos as infâncias presentes em classes multisseriadas do referido município.

Aliando à fotografia as memórias de ex-alunos, coletadas em roda de conversa com moradores antigos da comunidade e em entrevista com a primeira professora da escola, pudemos compreender mais amplamente o período no qual a unidade foi constituída na comunidade pomerana de Caramuru. Como mediador potente para a ativação da memória local, notadamente, como monumento e documento, a 
fotografia oferece importantes indícios ao aprofundamento dos estudos da historiografia da Educação Infantil campesina. Nesse sentido, interrogada a partir das perguntas feitas no presente, a fotografia se revela como parte de um processo vivo e atual.

O estudo permitiu compreender que a criação das escolas multisseriadas no contexto da comunidade campesina pomerana de Caramuru transcorreu em movimentos contraditórios: ao mesmo tempo em que elas representam o modelo republicano de escola, uma cópia da escola implantada no meio urbano, também são apropriadas pela comunidade para atendimento as suas demandas imediatas. Isso pode ser notado quando a comunidade escapa ao legalmente previsto. Por exemplo, as famílias enviavam à escola filhos que ainda não atendiam à idade mínima, mas que, pelos percalços oferecidos pelas condições da época, acabavam frequentando tal espaço na companhia dos irmãos maiores. Para ir à escola, arriscavam-se, caminhando grandes distâncias a pé.

A presença dos mais velhos poderia Ihes dar mais segurança, para, quando estivessem na idade formalmente aceita, não se sentissem temerosos durante as longas caminhadas. Adicionalmente, essa presença precoce na escola permitiria que eles ampliassem suas possibilidades de socialização e de aprendizagem da língua portuguesa, ambientando-se a uma situação que vivenciariam posteriormente, de forma oficial. Logo, a escola multisseriada campesina também representou um escape ao estabelecido.

Por isso, a inclusão da criança pequena na escola multisseriada é uma solução para a falta de políticas de atendimento às infâncias naquele contexto, alternativa, que, de algum modo, também contemplou as necessidades da mulher campesina de ter um lugar que Ihe ajudasse a prover cuidado aos filhos. Como acontece ainda hoje, ela acumulava funções domésticas com o trabalho no plantio, colheita e cuidado com os animais domésticos. Nessa perspectiva, os usos que as comunidades tradicionais 
pomeranas faziam das escolas multisseriadas, nos anos 1960, permitiram que elas se afirmassem como espaço de resistência da cultura e da língua da comunidade e, por suas práticas de produção material e simbólica, demarcassem o território.

\section{Referências}

BAHIA, J. Uma bela história a ser contada: os pomeranos no Estado do Espírito Santo. In: MELO, S. M.; SOUZA, M. T. (org.). Pomeranos no Brasil: olhares, vozes e histórias de um povo. Rio de Janeiro: Letras e Versos, 2015. p. 35-53.

BRANDÃO, C. R. A comunidade tradicional. 2012. Disponível em: http://nupaub.fflch.usp.br/sites/nupaub.fflch.usp.br/files/a\%20comunidade\%20trad 160.pdf. Acesso em: 03 maio 2019.

BRASIL. Resolução CNE/CP no 1, de 18 de fevereiro de 2002. Institui Diretrizes Curriculares Nacionais para a formação de professores da Educação Básica, em nível superior, curso de licenciatura, de graduação plena. Brasília, DF: fev. 2002. Disponível em: http://portal.mec.gov.br/seesp/arquivos/pdf/res1_2.pdf. Acesso em: 12 maio 2019.

BRASIL. Decreto no 6.040, de 7 de fevereiro de 2007. Institui a Política Nacional de Desenvolvimento Sustentável dos Povos e Comunidades Tradicionais. Brasília, DF: fev. 2007. Disponível em: http://www.planalto.gov.br/ccivil_03/_ato20072010/2007/decreto/d6040.htm. Acesso em: 03 maio 2019.

BRASIL. Resolução no 2, de 28 de abril de 2008. Estabelece diretrizes complementares, normas e princípios para o desenvolvimento de políticas públicas de atendimento da Educação Básica do Campo. Brasília, DF: abr. 2008. Disponível em: http://portal.mec.gov.br/arquivos/pdf/resolucao_2.pdf. Acesso em: 12 maio 2019.

BRASIL. Resolução no 5, de 17 de dezembro de 2009. Fixa as Diretrizes Curriculares Nacionais para a Educação Infantil. Brasília, DF: dez. 2009. Disponível em: http://portal.mec.gov.br/index.php?option=com_docman\&view=download\&alias=22 98-rceb005-09\&category_slug=dezembro-2009-pdf\&Itemid=30192. Acesso em: 12 maio 2019. 
BRASIL. Decreto no 7.352, de 4 de novembro de 2010. Dispõe sobre a política de educação do campo e o Programa Nacional de Educação na Reforma Agrária PRONERA. Brasília, DF: nov. 2010. Disponível em: http://portal.mec.gov.br/docman/marco-2012-pdf/10199-8-decreto-7352-de4-denovembro-de-2010/file. Acesso em: 16 de abr. de 2019.

BRASIL. Lei no 13.005, de 25 de junho de 2014. Aprova o Plano Nacional de Educação - PNE e dá outras providências. Brasília, DF: jun. 2014. Disponível em: http://www.planalto.gov.br/ccivil_03/_ato2011-2014/2014/lei//13005.htm. Acesso em: 03 maio 2019.

BRASIL. Decreto no 8.750, de 9 de maio de 2016. Institui o Conselho Nacional dos Povos e Comunidades Tradicionais. Brasília, DF: maio 2016. Disponível em: http://www.planalto.gov.br/ccivil_03/_Ato2015-2018/2016/Decreto/D8750.htm. Acesso em: 03 maio 2019.

CIAVATTA, M. O mundo do trabalho em imagens: a fotografia como fonte história (Rio de Janeiro, 1900-1930). Rio de Janeiro: DPA, 2002.

. Educando o trabalhador da grande família da fábrica: a fotografia como fonte histórica. In: CIAVATTA, M.; ALVES, N. (org.). A leitura de imagens na pesquisa social: história, comunicação e educação. São Paulo: Cortez, 2008. p. 37-59.

DELBONI, J. H. B. Imagem e memória: uma análise da escola multisseriada nas comunidades do campo em Santa Maria de Jetibá-ES. 2016. Dissertação (Mestrado em Educação) - Programa de Pós-graduação em Educação, Universidade Federal do Espírito Santo, Vitória, 2016. Disponível em:

http://repositorio.ufes.br/handle/10/8653. Acesso em: 3 maio 2019.

DETTMANN, J. M. Práticas e saberes da professora pomerana: um estudo sobre interculturalidade. 2014. Dissertação (Mestrado em Educação) - Programa de Pósgraduação em Educação, Universidade Federal do Espírito Santo, Vitória, 2014. Disponível em: http://repositorio.ufes.br/handle/10/2438. Acesso em: 20 de maio de 2019.

FOERSTE, E. Questões sobre língua pomerana e interculturalidade em um contexto no Brasil. In: BORN, J.; LADILOVA, A. (org.). Sprachkontakte des Portugiesichen. Frankfurt am Main: Peter Lang Edition, 2016. p. 13-32.

FOERSTE, E.; SCHÜTZ-FOERSTE, G. M. Educador do campo, um intelectual orgânico? 
(memórias em imagens de D. Arlete). In: CONGRESSO INTERNACIONAL DE PEDAGOGIA SOCIAL, 4., 2012, São Paulo, Campinas. Anais [...]. São Paulo, Campinas: PUC, USP, MAKENZIE, UNICAMP, UNISAL, 2012. Disponível em: http://www.proceedings.scielo.br/pdf/cips/n4v1/34.pdf. Acesso em: 18 maio 2019.

FOERSTE, E.; SCHÜTZ-FOERSTE, G. M. Língua, cultura e educação do povo tradicional pomerano. Educação em Revista, Belo Horizonte, v. 33, n. 2, p. 9-32, abr./jun. 2017. Disponível em https://www.researchgate.net/publication/316028440_LINGUA_CULTURA_E_EDUCA CAO_DO_POVO_TRADICIONAL_POMERANO. Acesso em: 18 maio 2019.

FOERSTE, E.; SCHÜTZ-FOERSTE, G. M.; MERLER, A. Memórias e imagens da formação do professor do campo no Brasil. Visioni Latinoamericane, v. 11, p. 7-22, 2014. Disponível em: https://www.openstarts.units.it/bitstream/10077/10221/1/VLA_2014_11_01_Foerst e_Merler.pdf. Acesso em: 18 maio 2019.

FREIRE, P. Pedagogia do oprimido. Rio de Janeiro: Paz e Terra, 1970.

HARTUWIG, A. V. G. Professores(as) pomeranos(as): um estudo de caso sobre o Programa de Educação Escolar Pomerana PROEPO desenvolvido em Santa Maria de Jetibá/ES. 2011. Dissertação (Mestrado em Educação) - Programa de Pós-graduação em Educação, Universidade Federal do Espírito Santo, Vitória, 2011. Disponível em: http://repositorio.ufes.br/bitstream/10/2294/1/tese_5625_ADRIANA\%20VIEIRA\%20 GUEDES\%2OHARTUWIG.pdf. Acesso em: 18 maio 2019.

IBGE. Pesquisa nacional por amostra de domicílios: síntese de indicadores 2009. Rio de Janeiro: IBGE, 2010.

INEP. Sinopse Estatística da Educação Básica 2018. Brasília, DF: IBGE, 2019.

Disponível em: http://inep.gov.br/web/guest/sinopses-estatisticas-da-educacaobasica. Acesso em: 21 maio 2019.

KOELER, E. Uma professora pomerana e sua comunidade. 2016. Dissertação (Mestrado em Educação) - Programa de Pós-graduação em Educação, Universidade Federal do Espírito Santo, Vitória, 2016. Disponível em: http://repositorio.ufes.br/handle/10/8586. Acesso em: 18 maio 2019.

KOSIK, K. Dialética do concreto. Rio de Janeiro: Paz e Terra, 1976.

KÜSTER, S. B. Cultura e língua pomeranas: um estudo de caso em uma escola do 
ensino fundamental no município de Santa Maria de Jetibá - Espírito Santo - Brasil. 2015. Dissertação (Mestrado em Educação) - Programa de Pós-graduação em Educação, Universidade Federal do Espírito Santo, Vitória, 2015. Disponível em: http://repositorio.ufes.br/handle/10/2460. Acesso em: 18 de maio de 2019.

LE GOFF, J. História e memória. Campinas: Editora da Unicamp, 1990.

MORETO, C. Gerações de professoras de classes multisseriadas do campo. 2015. Tese (Doutorado em Educação) - Programa de Pós-graduação em Educação, Universidade Federal do Espírito Santo, Vitória, 2015. Disponível em: http://repositorio.ufes.br/handle/10/1584?locale=pt_BR. Acesso em: 3 maio 2019.

MÜLLER, E. R. Classe multisseriada em Domingos Martins/ES: um estudo de caso sobre cultura escolar e cultura da escola. 2019. Dissertação (Mestrado em Educação) - Programa de Pós-graduação em Educação, Universidade Federal do Espírito Santo, Vitória, 2019. Disponível em: http://repositorio.ufes.br/jspui/handle/10/11075. Acesso em: 3 maio 2019.

SANTA MARIA DE JETIBÁ (ES). Lei no 1.136, de 26 de junho de 2009. Dispõe sobre a cooficialização da língua pomerana no município de Santa Maria de Jetibá, estado do Espírito Santo. Santa Maria de Jetibá, ES, 26 jun. 2009. Disponível em:

https://leismunicipais.com.br/a/es/s/santa-maria-de-jetiba/leiordinaria/2009/114/1136/lei-ordinaria. Acesso em: 20 maio 2019.

SANTOS, M. O dinheiro e o território. Geographia, Niterói, v. 1, n. 1, p. 7-13, 1999. Disponível em: http://periodicos.uff.br/geographia/article/view/13360/0. Acesso em: 18 maio 2019.

SARMENTO, M. J. As culturas da infância nas encruzilhadas da segunda modernidade. In: SARMENTO, M. J.; CERISARA, A. B. (org.). Crianças e miúdos: perspectivas sociopedagógicas da infância e educação. Porto: Asa, 2004. p. 9-34.

Sociologia da infância: correntes e confluências. In: SARMENTO, M. J.; GOUVÊA, M. C. S. (org.). Estudos da infância: educação e práticas sociais. Petrópolis: Vozes, 2008. p. 17-39.

SILLER, R. R.; ARAÚJO, V. C. A criança pomerana na educação infantil: posso falar minha língua aqui? Revista Educação (UFSM), Santa Maria, v. 44, p. 1-19, 2019. Disponível em: https://periodicos.ufsm.br/reveducacao/article/view/34697. Acesso em: 18 maio 2019. 
WEBER, M. G. A escolarização entre descendentes pomeranos em Domingos

Martins. 1998. Dissertação (Mestrado em Educação) - Programa de Pós-graduação em Educação, Universidade Federal do Espírito Santo, Vitória, 1998.

Enviado em: $28 / 05 / 2019$

Aprovado em: $14 / 02 / 20$ 